\title{
Indomethacin attenuates mechanical allodynia during the organization but not the maintenance of the peripheral neuropathic pain induced by nervus ischiadicus chronic constriction injury
}

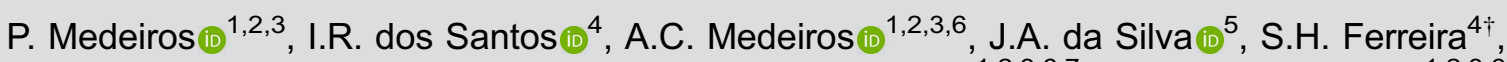 \\ R.L. de Freitas (10) ${ }^{1,2,3,6,7}$, and N.C. Coimbra (i) ${ }^{1,2,3,6}$ \\ ${ }^{1}$ Laboratório de Neurociências da Dor \& Emoções, Departamento de Cirurgia e Anatomia, Faculdade de Medicina de Ribeirão \\ Preto, Universidade de São Paulo, Ribeirão Preto, SP, Brasil \\ ${ }^{2}$ Centro Multiusuários de Neuroeletrofisiologia, Departamento de Cirurgia e Anatomia, Faculdade de Medicina de Ribeirão Preto, \\ Universidade de São Paulo, Ribeirão Preto, SP, Brasil \\ ${ }^{3}$ Laboratório de Neuroanatomia e Neuropsicobiologia, Departamento de Farmacologia, Faculdade de Medicina de Ribeirão Preto, \\ Universidade de São Paulo, Ribeirão Preto, SP, Brasil \\ ${ }^{4}$ Laboratório de Dor e Imflamação, Departamento de Farmacologia, Faculdade de Medicina de Ribeirão Preto, Universidade de \\ São Paulo, Ribeirão Preto, SP, Brasil \\ ${ }^{5}$ Departamento de Psicologia, Universidade Federal de Juiz de Fora, Juiz de Fora, MG, Brasil \\ ${ }^{6}$ Instituto de Neurociências e Comportamento, Ribeirão Preto, SP, Brasil \\ ${ }^{7}$ Instituto de Ciências Biomédicas, Universidade Federal de Alfenas, Alfenas, MG, Brasil
}

\begin{abstract}
The neurochemical mechanisms underlying neuropathic pain (NP) are related to peripheral and central sensitization caused by the release of inflammatory mediators in the peripheral damaged tissue and ectopic discharges from the injured nerve, leading to a hyperexcitable state of spinal dorsal horn neurons. The aim of this work was to clarify the role played by cyclooxygenase (COX) in the lesioned peripheral nerve in the development and maintenance of NP by evaluating at which moment the nonsteroidal anti-inflammatory drug indomethacin, a non-selective COX inhibitor, attenuated mechanical allodynia after placing one loose ligature around the nervus ischiadicus, an adaptation of Bennett and Xie's model in rodents. NP was induced in male Wistar rats by subjecting them to chronic constriction injury $(\mathrm{CCl})$ of the nervus ischiadicus, placing one loose ligature around the peripheral nerve, and a sham surgery (without $\mathrm{CCl}$ ) was used as control. Indomethacin $(2 \mathrm{mg} / \mathrm{kg}$ ) or vehicle was intraperitoneally and acutely administered in each group of rats and at different time windows (1, 2, 4, 7, 14, 21, and 28 days) after the $\mathrm{CCl}$ or sham surgical procedures, followed by von Frey's test for $30 \mathrm{~min}$. The data showed that indomethacin decreased the mechanical allodynia threshold of rats on the first, second, and fourth days after $\mathrm{CCl}(\mathrm{P}<0.05)$. These findings suggested that inflammatory mechanisms are involved in the induction of NP and that COX-1 and COX-2 are involved in the induction but not in the maintenance of NP.
\end{abstract}

Key words: Non-steroidal anti-inflammatory drugs; Indomethacin; Chronic constriction injury of the nervus ischiadicus; Neuropathic pain; Mechanical allodynia; von Frey test

\section{Introduction}

According to the International Association for the Study of Pain (IASP), pain is an unpleasant sensory and emotional experience associated with actual or potential tissue injury or described regarding such damage (1). Pain is a signal to prevent further lesion or to avoid tissue injury. The genesis and duration of chronic pain are critically different from those of acute pain, and the underlying mechanisms of chronic pain need to be more deeply studied (2).

Neuropathic pain (NP) is related to the reaction of nervous system tissue to neural damage. NP can be induced by lesions of the peripheral nervous system

Correspondence: N.C. Coimbra: <nccoimbr@fmrp.usp.br>

$\dagger$ In Memoriam

Received October 20, 2019 | Accepted February 26, 2020 
(PNS) caused by tumor invasion, metabolic diseases, infection, neurotoxic chemicals, and mechanical trauma leading to pathophysiological changes in either the PNS or the central nervous system (CNS) (3).

The incidence of chronic pain in the world is approximately $8 \%(4-5)$. The prevalence of NP is estimated to be $23 \%(5)$. NP is an unpleasant and debilitating condition that causes a severe impact on the quality of life of patients (6). The management of patients affected by NP is complicated, involving a multidisciplinary team for alleviating symptoms and available treatments are frequently ineffective.

Thus far, several models of peripheral NP have been developed in rodents. These experimental neurological procedures aim to mimic the clinical symptoms reported in humans after central or peripheral nerve injury, diabetic neuropathy, chemotherapy, and inflammation. The majority of NP models in rodents are based on the compression or section of the targeted nerve (7).

The nervus ischiadicus chronic constriction injury (CCl) model, as proposed by Bennett et al. (8), is an animal model of peripheral neuropathy. We have recently reported an improvement in this procedure in a laboratory animal model of $\mathrm{NP}$, inducing $\mathrm{CCl}$ of the right nervus ischiadicus through a single loose ligature in an adaptation of the NP model described by Bennett and Xie in 1988 (9-11). The modified model produced sensory, affective, and cognitive disorders in rodents (9-12). In addition, mechanical allodynia has been recorded twenty-one days after nervus ischiadicus $\mathrm{CCl}$ surgery $(10,11)$.

In fact, NP manifests itself through neurochemical changes in both the PNS and the CNS, affecting the peripheral nerve, spinal, and cortical structures (13). In the periphery, neuropathic lesions trigger peripheral sensitization that induces an inflammatory process and abnormal long-term neural activity along the primary afferent pathways (14).

Non-steroidal anti-inflammatory drugs (NSAIDs) are used to treat pain and reduce fever, and they have antiinflammatory properties (15). Non-selective and selective cyclooxygenase (COX) inhibitors are partially effective in reducing NP symptoms induced by partial transection of the nervus ischiadicus (16), indicating that pro-inflammatory prostaglandins are involved in NP. In the present study, we evaluated whether indomethacin, an NSAID that inhibits the cyclooxygenase 1 and 2 (COX-1 and COX-2) enzymes, can attenuate mechanical allodynia in an adapted $\mathrm{CCl}$ model of NP generated by placing a single loose ligature around a peripheral nerve.

\section{Material and Methods}

\section{Animals and housing conditions}

Adult male Wistar rats $(n=208)$, weighing 250-300 g, from the animal care facility of the University of São Paulo (USP; Campus of Ribeirão Preto) were used. Animals were housed in groups of four with free access to food and water. The housing room was kept at constant room temperature $\left(22 \pm 1^{\circ} \mathrm{C}\right)$ and illuminated on a fixed light-dark cycle (lights on 07:00-19:00 h). All protocols were in compliance with the recommendations of the Committee for Ethics in Animal Experimentation of the Ribeirão Preto Medical School of the University of São Paulo (Processes $015 / 2005$ and 036/2017), which agree with the animal research ethics adopted by the National Council for Animal Experimentation Control and with the IASP guidelines for pain research on animals (17). Each animal was used in a single experimental group and all efforts were made to minimize their discomfort.

\section{Neuropathic pain induction}

An adapted model of chronic constriction injury $(\mathrm{CCl})$ of the nervus ischiadicus was used to induce NP. A single ligature consisting of a chromic catgut suture (Bioline Fios Cirúrgicos Ltda., Brazil) was loosely placed around the right nervus ischiadicus (9-12). Each animal, in turn, was anesthetized with a mixture of ketamine (União Química Farmacêutica Nacional, Brazil) and xylazine (Hertape/ Calier, Brazil) (92 mg/kg and $9.2 \mathrm{mg} / \mathrm{kg}$, respectively, ip). The right hind paw was shaved and moistened with a disinfectant, and the common nervus ischiadicus was exposed at the mid-thigh level by blunt dissection through the biceps femoris. Then, proximal to the nervus ischiadicus trifurcation, approximately $7 \mathrm{~mm}$ of the nerve was freed of adhering tissues, and one loose ligature (4.0 chromic gut) was placed around the peripheral nerve. The wound was then closed by suturing the muscle with chromic catgut in a continuous suture pattern. Finally, the skin was closed with 3-0 black braided silk sutures (Teleflex Medical OEM, USA) in a horizontal mattress suture pattern. Sham surgery was performed by exposing the nervus ischiadicus as described above, without ligation. The animals were then transferred to their home cages and left to recover.

\section{Measurement of mechanical allodynia}

Mechanical allodynia was assessed by von Frey test filaments (Stoelting, USA). Each animal was placed in a transparent acrylic cage $(22 \times 16.5 \times 14 \mathrm{~cm})$ with a wiregrid floor for approximately $20 \mathrm{~min}$ to allow behavioral acclimation to the novel environment before testing. von Frey's filaments were then applied through the mesh floor in ascending order from 10 to $100 \mathrm{~g}$ to the plantar surface at the center of the paw or the base of the third or fourth toe of the injured and uninjured hind paw for approximately 3-4 s per filament to induce the withdrawal reflex. The time interval before the application of the next filament was at least $10 \mathrm{~s}$. The data are reported as mechanical withdrawal thresholds (MWTs) in grams. The MWT was evaluated before and after $\mathrm{CCl}$ or sham surgery and before and after pharmacological treatments. The test was repeated three times for both hind paws (ipsilateral and contralateral paws were tested in alternation) with an interval of at least $2 \mathrm{~min}$ 
between measurements. Before surgery, it was confirmed that there was no difference in the basal responses of the right and left paws (18).

\section{Systemic drug administration: effect of indomethacin on mechanical allodynia}

To evaluate an NSAID that inhibits COX-1 and COX-2 during NP, indomethacin (2 mg/kg) (19) (or vehicle) was intraperitoneally and acutely administered in each group of rats at different time windows $(1,2,4,7,14,21$, and 28 days) after $\mathrm{CCl}$ or sham surgical procedures (day 0). Mechanical allodynia was measured at 0,15 , and $30 \mathrm{~min}$ after the intraperitoneal drug or vehicle administration. The time point of 0 min marked the end of the 40-min interval after the intraperitoneal administration of drugs (Figure 1) $(20,21)$.

The animals were subjected to the experimental tests in the light phase of the light-dark cycle, and the treatment was always performed at the same time of the day and by the same researcher. The sessions were performed by a trained researcher who analyzed the experimental data in a blinded manner. After the end of the experimental test, the animals were euthanized with ketamine $(92 \mathrm{mg} / \mathrm{kg}$ ) and xylazine $(9.2 \mathrm{mg} / \mathrm{kg})$.

\section{Drugs}

1-(4-Chlorobenzoyl)-5-methoxy-2-methyl-3-indoleacetic acid (indomethacin) $(2 \mathrm{mg} / \mathrm{kg}$ ) (Sigma-Aldrich Brazil, Brazil) was diluted in Tris/ $\mathrm{HCl}$ (2-amino-2-(hydroxymethyl) propane-1,3-diol/hydrochloric acid) buffer, $\mathrm{pH}$ 8.0.

\section{Statistical analysis}

Data are reported as means $\pm S E$. The mechanical allodynia results from the von Frey test were analyzed by a repeated-measures two-way analysis of variance (ANOVA). In the case of a significant treatment-by-time interaction, one-way ANOVAs were performed, followed by Duncan's post hoc test at each time interval. $\mathrm{P}<0.05$ was considered statistically significant. The software used for statistical analyses was SPSS 13 (IBM, USA), and the graphs were plotted in GraphPad Prism version 7.0 (USA).

\section{Results}

\section{Effect of indomethacin on mechanical allodynia}

Animals of $\mathrm{CCl}$ group showed mechanical allodynia at $1,2,4,7,14,21$, and 28 days after $\mathrm{CCl}$. The systemic administration of indomethacin attenuated mechanical allodynia at 1,2 , and 4 days after $\mathrm{CCl}$ induction. No change was observed in the MWT in the contralateral paw of the $\mathrm{CCl}$ or sham procedure (not shown).

At day 1 after $\mathrm{CCl}$, there were statistically significant effects of treatment $\left[F_{(3,28)}=18.89 ; P<0.0001\right]$ and of time $\left[\mathrm{F}_{(4,25)}=15.53 ; \mathrm{P}<0.0001\right]$ on the MWT, as well as a significant treatment-by-time interaction $\left[F_{(12,71)}=11.43\right.$; $\mathrm{P}<0.0001]$. There was a significant decrease in mechanical allodynia in rats after indomethacin administration compared with vehicle administration at the 15- and 30-min time points $(P<0.05)$, according to Duncan's post hoc test (Figure 2A).

At day 2 after $\mathrm{CCl}$ induction, there were statistically significant effects of treatment $\left[F_{(3,25)}=12.55 ; \mathrm{P}<0.0001\right]$ and of time $\left[\left(F_{(4,22)}=5.70 ; P<0.01\right]\right.$ on the MWT, as well as a significant treatment-by-time interaction $\left[F_{(12,62)}=3.26\right.$; $P<0.01$ ], according to the repeated-measures two-way ANOVA. Treatment with indomethacin significantly attenuated mechanical allodynia $(P<0.05$, Duncan's post hoc test) at $15 \mathrm{~min}$ after administration in $\mathrm{CCl}$ rats. Indomethacin also increased the MWT at 15 min after administration in the sham group compared with the vehicle-treated sham group (Figure 2B), and this effect was statistically significant.

At day 4 , there were statistically significant effects of treatment $\left[F_{(3,27)}=16.43 ; P<0.0001\right]$ and of time $\left[F_{(4,24)}=\right.$ 3.71; $\mathrm{P}<0.01$ ] on the MWT, as well as a significant treatment-by-time interaction $\left[F_{(12,68)}=4.63 ; P<0.0001\right]$. Indomethacin decreased mechanical allodynia at 15 and 30 min after administration (Duncan's post hoc test; $\mathrm{P}<0.05$ ) (Figure 2C).

At 7 days after $\mathrm{CCl}$, analysis of the MWT showed significant effects of treatment $\left[F_{(3,28)}=54,97 ; P<0.0001\right]$ and of time $\left[F_{(4,25)}=4.25 ; \mathrm{P}<0.001\right]$, as well as a significant

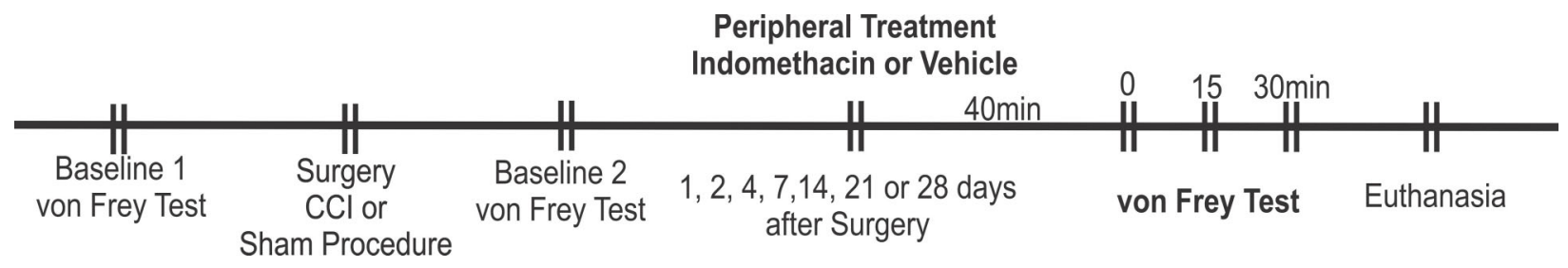

Figure 1. Timeline of the experimental procedure. The animals ( $n=6$ to 9 per group) were divided into four groups: vehicle/sham, vehicle/ chronic constriction injury $(\mathrm{CCl})$, indomethacin/sham, and indomethacin/CCl. The mechanical-stimulus-induced response threshold was measured once before the $\mathrm{CCl}$ or sham procedures (day 0 ) and once 1, 2, 4, 7, 14, 21, or 28 days after surgery. Pretreatment with indomethacin $(2 \mathrm{mg} / \mathrm{kg})$ or vehicle was performed intraperitoneally, and indomethacin or vehicle was acutely administered in each group of rats. Mechanical allodynia was measured at 0,15 , and $30 \mathrm{~min}$ after the intraperitoneal drug or vehicle administration. The time point of 0 min indicates the end of the 40-min interval after the intraperitoneal administration of drugs. Subsequently, the animals were euthanized. 


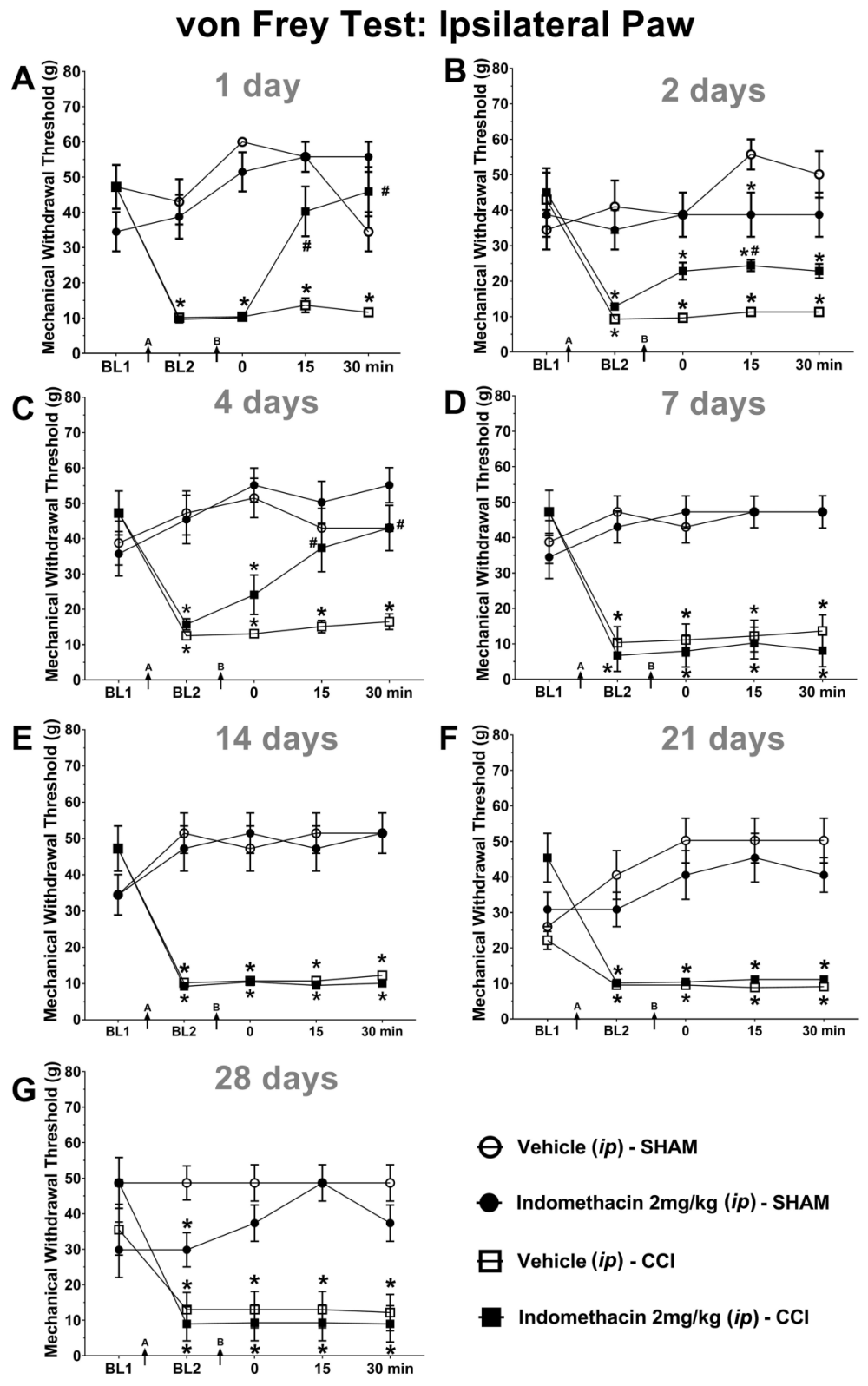

Figure 2. A to G, Effect of the intraperitoneal (ip) administration of indomethacin on the genesis and maintenance of neuropathic pain induced by an adapted model of chronic constriction injury $(\mathrm{CCl})$ of the nervus ischiadicus in the right hind paw of Wistar rats. BL1: von Frey's test baseline was recorded before each procedure. Arrow A: Nervus ischiadicus CCl or sham procedure. BL2: New baseline recorded at 1, 2, 4, 7, 14, 21, and 28 days after the sham or CCl procedure. Arrow B: Administration of indomethacin or vehicle in rats subjected to sham or $\mathrm{CCl}$ procedures (von Frey's test applied to the ipsilateral paw until $30 \mathrm{~min}$ after injection). The data are reported as means $\pm \mathrm{SE}$. ${ }^{*} \mathrm{P}<0.05$, compared with the sham-vehicle treated group; ${ }^{\#} \mathrm{P}<0.05$ compared with the CCl-vehicle-treated group (repeated-measures two-way ANOVA followed by Duncan's post hoc test).

treatment-by-time interaction $\left[\mathrm{F}_{(12,71)}=4.28 ; \mathrm{P}<0.0001\right]$; at 14 days after $\mathrm{CCl}$, analysis showed significant effects of treatment $\left[F_{(3,28)}=27.56 ; P<0.0001\right]$ and of time $\left[F_{(4,25)}=\right.$ 4.02; $\mathrm{P}<0.01$ ], as well as a significant treatment-by-time interaction $\left[\mathrm{F}_{(12,71)}=7.09 ; \mathrm{P}<0.0001\right]$; at 21 days after $\mathrm{CCl}$, there were significant effects of treatment $\left[F_{(3,24)}=24.72\right.$; $\mathrm{P}<0.0001]$ and of time $\left[\mathrm{F}_{(4,21)}=3.28 ; \mathrm{P}<0.05\right]$, as well as a significant treatment-by-time interaction $\left[F_{(12,59)}=7.05\right.$; $\mathrm{P}<0.0001]$ according to the repeated-measures two-way ANOVA followed by Duncan's post hoc test. Indomethacin 


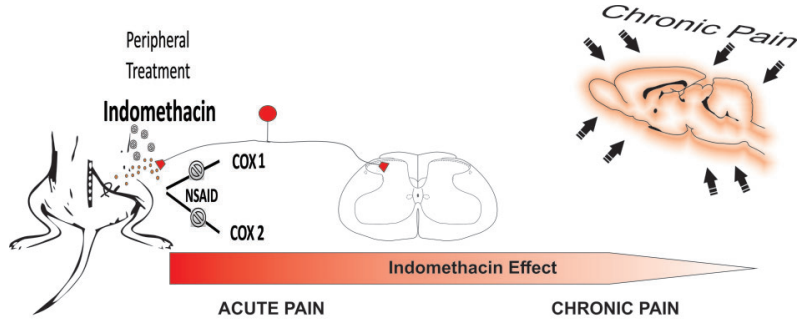

Figure 3. The peripheral treatment with the nonsteroidal antiinflammatory drug (NSAID) indomethacin attenuates mechanical allodynia during the organization (acute pain) but not the maintenance (chronic pain) of peripheral neuropathic pain induced by nervus ischiadicus chronic constriction injury. Indomethacin did not modify chronic neuropathic pain. Supraspinal and cortical areas participate in the chronic stages of neuropathic pain.

did not modify the MWT in sham or $\mathrm{CCl}$ rats at days 7, 14, or 21 after surgery (Figure 2D to $\mathrm{F}$ ).

At 28 days after $\mathrm{CCl}$, there were significant effects of treatment $\left[F_{(3,20)}=10.81 ; P<0.0001\right]$ and of time $\left[F_{(4,17)}=\right.$ 10.86; $\mathrm{P}<0.0001]$ on the MWT, as well as a significant treatment-by-time interaction $\left[F_{(12,47)}=4.21 ; P<0.0001\right]$, according to the repeated-measures two-way ANOVA. The postsurgical baseline MWT values of sham rats treated with vehicle were significantly different from those of sham rats treated with indomethacin $(2 \mathrm{mg} / \mathrm{kg}$, ip) (Duncan's post hoc test, $\mathrm{P}<0.05$ ) (Figure $2 \mathrm{G}$ ).

The data of the effects of indomethacin $(2 \mathrm{mg} / \mathrm{kg}, i p)$ on mechanical allodynia are reported in Supplementary Table S1.

\section{Discussion}

In this study, the Wistar rats subjected to the adapted model of $\mathrm{CCl}$ using only one ligature around the nervus ischiadicus showed mechanical allodynia. The NSAID indomethacin, a non-selective COX inhibitor, attenuated mechanical allodynia during the first stage of NP development (from the first to the fourth day after the $\mathrm{CCl}$ procedure).

In fact, the pharmacological treatments of pain, including pregabalin (a lipophilic GABA analogue with a substitution at the 3'-position to facilitate diffusion across the blood-brain barrier), gabapentin (another analogue of GABA), duloxetine (a serotonin and noradrenaline reuptake inhibitor), and various tricyclic antidepressants, have strong recommendations for use and are recommended as first-line treatments for peripheral and central neuropathic pain $(22,23)$. Such approaches are usually associated to NSAIDs (24) and opioid analgesics. Indomethacin is a synthetic NSAID introduced in the early 1960s (25) and was initially utilized for the treatment of pain and inflammation from rheumatological diseases. Inhibiting the release and biosynthesis of prostaglandins, indomethacin has antipyretic, analgesic, and anti-inflammatory properties (19, 26-28). In addition, indomethacin acts through the inhibition of the COX enzymes, consisting of an important therapeutic intervention for the management of acute and chronic pain (29).

The pharmacological target of NSAIDs are the enzymes that catalyze the conversion of arachidonic acid in prostaglandins (PGs), which are the main mediators of exaggerated pain sensation (29-30). Therefore, PGs may play an important role in the induction of NP. NSAIDs are strong COX inhibitors that are used in the management of chronic, inflammatory, and postoperative pain (31). However, they have serious side effects (gastro-intestinal complications and, at high levels, hepatotoxicity and nephrotoxicity) (32-33), which make them not very safe choices for the long-term management of chronic pain.

In the current study, indomethacin attenuated mechanical allodynia until the fourth day after $\mathrm{CCl}$ induction, whereas it proved to be ineffective from the seventh to the twenty-eighth days after $\mathrm{CCl}$. Indeed, the treatment with indomethacin decreased the mechanical allodynia during the initial phase rather than during the chronic phase when that effect was not observed. These findings could be explained if we consider that the sensitization of supraspinal nociceptive transmission might be involved in the expression of chronic pain (34). Interestingly, indomethacin attenuated mechanical allodynia at 15 and 30 min after the application of mechanical stimuli. Intraperitoneal treatment with indomethacin caused a much higher effect at the first and fourth days compared to the second day after the peripheral nerve injury, possibly because of the biological variability of the laboratory animals. It is also possible that on the second day after $\mathrm{CCl}$ of the nervus ischiadicus, more pronounced inflammatory reactions can surpass the pharmacological effect of indomethacin. In fact, after the nerve injury, Schwann cells and resident immune cells such as mast cells and macrophages are the first to react against cellular injury.

Molecular signaling from damaged axons results in the activation of the extracellular stimulus-related (ERK) mitogen-activated protein (MAP) kinase signaling pathway in Schwann cells, as one of the earliest events triggering the release of inflammatory mediators and recruiting immune cells to the damaged nerve (35). Resident mast cells degranulate inflammatory mediators, including histamine, serotonin, nerve growth factor, and leukotrienes, which can sensitize nociceptors and also contribute to the recruitment of neutrophils, the first cells to infiltrate damaged tissue. Neutrophil infiltration to the site of injury is acute, peaking within the first few hours after injury and declining after 3 days, with levels remaining elevated (36). Then, that phenomenon could explain the fact that on the second day after the injury the IP-treatment with indomethacin caused lower effects.

Peripheral nerve damage can result in chronic NP in multiple ways (37). While the insult may be localized in a specific division of either the PNS or the CNS, the pathophysiological response that leads to chronic pain is diffuse. Peripheral terminals of pain-processing unmyelinated 
C-fibers and thinly myelinated $A \delta$ fibers can spur the development of NP after being affected by metabolic damage, toxins, medications, cytokines, and other inflammatory mediators (38), resulting in fiber density changes and neuronal hyper-excitability (39).

For example, a short-lived inflammation was induced in a rat hind paw by intradermal injection of a very low dose of the inflammogen carrageenan. The resultant inflammation (localized redness with minimal swelling) was associated with acute hyperalgesia, detected as a decrease in the threshold for the withdrawal response to a mechanical pressure stimulus applied to the inflamed paw. Both acute inflammation and the associated hyperalgesia resolved within 4 days, and the animal was left with no signs of ongoing inflammation or hyperalgesia. Indeed, carrageenan injection is often used as a model of simple acute inflammatory pain. However, when the paw was challenged with a new inflammatory stimulus, even weeks later, a dramatically enhanced hyperalgesic response was apparent (38). Thus, the injection of a low dose of an inflammatory cytokine, e.g., prostaglandin $E_{2}\left(P E_{2}\right)$, which in a naive rat paw would cause only brief hyperalgesia lasting less than $4 \mathrm{~h}$, now evoked hyperalgesia lasting at least $24 \mathrm{~h}$. In addition to this prolongation, hyperalgesic priming also causes an increase in the magnitude of hyperalgesia: the dose-response relationship for $P G E_{2}$-induced hyperalgesia is shifted to the left by more than one order of magnitude (40).

Indomethacin, in the present study, did not modify the chronic NP. Supraspinal and cortical areas participate in the chronic stages of NP (14). Supporting this point of view, Medeiros et al. (11) demonstrated a key role played by the rostral divisions of the frontal cortex in the elaboration of the chronic stages of NP. In fact, the prelimbic division of the medial prefrontal cortex (PrL$\mathrm{mPFC}$ ) is critically implicated in the chronic pain phenomenon twenty-one days after the adapted nervus ischiadicus $\mathrm{CCl}$ procedure to produce mechanical allodynia. The synaptic function blocker cobalt chloride, when microinjected into the PrL-mPFC cortex, attenuated mechanical allodynia twenty-one and twenty-eight but not seven and fourteen days after the nervus ischiadicus $\mathrm{CCl}$ (11).

In accordance with $\mathrm{Xu}$ and collaborators (13), the pathophysiological mechanisms that underlie the genesis and potentiation of NP have three stages: first, the peripheral nerve suffering the induction of pain, followed by

\section{References}

1. Merskey $\mathrm{H}$, Bogduk N. Classification of chronic pain. IASP Pain Terminology; 1994. p 240.

2. Wang LX, Wang ZJ. Animal and cellular models of chronic pain. Adv Drug Deliv Rev 2003; 55: 949-965, doi: 10.1016/ S0169-409X(03)00098-X. spinal cord neuronal activation, and finally a supraspinal or cortical potentiation. The transmission of noxious stimuli from peripheral receptors to the cerebral cortex involves multiple central ascending pathways. Concerning that, indomethacin has a peripheral action modulating the induction of neuropathic pain, and supraspinal/cortical regions are recruited later during the chronification of NP, which could explain the failure of indomethacin during the later phase of the chronic neuropathic pain phenomenon (Figure 3).

\section{Supplementary Material}

Click here to view [pdf].

\section{Acknowledgments}

This research was supported by Fundação de Amparo à Pesquisa do Estado de São Paulo (FAPESP) (Research grant 2013/12916-0 and Multi-User Equipment grant 2014/11869-0) and Conselho Nacional de Pesquisa e Desenvolvimento Tecnológico (CNPq) (grants 483763/ 2010-1, 474853/2013-6, and 427397/2018-9). Renato Leonardo de Freitas was supported by FAPESP (Scientific Initiation Scholarship grant 2001/03752-6, M.Sc. fellowship grant 2003/05256-1, post-doctoral fellowship grant 2009/17258-5, and researcher fellowship grant 2014/07902-2) and CAPES (Sc.D. fellowship grant 001). FAPESP also supported Priscila de Medeiros (Sc.D. fellowship grant 2012/25167-2, post-doctoral fellowship grant 2017/13560-5). Norberto Cysne Coimbra is a researcher (level 1A) from CNPq (processes 301905/ 2010-0 and 301341/2015-0). Sérgio Henrique Ferreira was supported by FAPESP (thematic project processes 2011/19670-0 and 2013/08216-2; Centre for Research in Inflammatory Diseases - CRID), the University of São Paulo Pro-Rectory (process NAP-DIN 11.1.21625.01.0), the European Union Seventh Framework Programme (FP7-2007-2013; HEALTH-F4-2011-281608), and CNPq (Brazil). The authors thank Daoud Hibrahim Elias-Filho, leda R. dos Santos, and Maria Rossatto for their expert technical assistance. D.H. Elias-Filho was the recipient of technician scholarships from FAPESP (TT-2, grant. 2002/ 01497-1), CNPq (grants 501858/2005-9, 372654/2006-1, $372810 / 2008-0,372877 / 2010-9$, and 372838/2018-9), and FAEPA (grants 345/2009 and 185/2010).
3. Woolf CJ, Mannion RJ. Neuropathic pain: Aetiology, symptoms, mechanisms, and management. Lancet 1999; 353: 1959-1964, doi: 10.1016/S0140-6736(99)01307-0.

4. Elliott AM, Smith BH, Hannaford PC, Smith WC, Chambers WA. The course of chronic pain in the community: results of 
a 4-year follow-up study. Pain 2002; 99: 299-307, doi: 10.1016/S0304-3959(02)00138-0.

5. Velly $A M$, Mohit S. Epidemiology of pain and relation to psychiatric disorders. Prog Neuro-Psychopharmacology Biol Psychiatry 2018; 87: 159-167, doi: 10.1016/j.pnpbp.2017. 05.012.

6. Gureje O, Von Korff M, Simon GE, Gater R. Persistent pain and well-being: a World Health Organization study in primary care. JAMA 1998; 280: 147-151, doi: 10.1001/jama.280.2. 147.

7. Jarvis MF, Boyce-Rustay JM. Neuropathic pain: models and mechanisms. Curr Pharm Des 2009; 15: 1711-1716, doi: 10.2174/138161209788186272.

8. Bennett GJ, Xie YK. A peripheral mononeuropathy in rat that produces disorders of pain sensation like those seen in man. Pain 1988; 33: 87-107, doi: 10.1016/0304-3959(88)90209-6.

9. Medeiros $P$, de Freitas RL, Boccella S, lannotta M, Belardo $C$, Mazzitelli $M$, et al. Characterization of the sensory, affective, cognitive, biochemical, and neuronal alterations in a modified chronic constriction injury model of neuropathic pain in mice. J Neurosci Res 2020; 98: 338-352, doi: 10. 1002/jnr.24501.

10. Medeiros P, Negrini-Ferrari SE, Medeiros AC, Ferreira LL, da Silva JRT, da Silva JA, et al. The primary motor cortex stimulation attenuates cold allodynia in a chronic peripheral neuropathic pain condition in Rattus norvegicus. World $\mathrm{J}$ Neurosci 2019; 09: 138-152, doi: 10.4236/wjns.2019.93009.

11. Medeiros $P$, Negrini-Ferrari SE, Palazzo E, Maione S, Ferreira $\mathrm{SH}$, de Freitas $\mathrm{RL}$, et al. N-methyl-d-aspartate receptors in the prelimbic cortex are critical for the maintenance of neuropathic pain. Neurochem Res 2019; 44: 2068-2080, doi: 10.1007/s11064-019-02843-z.

12. Dias QM, Rossaneis AC, Fais RS, Prado WA. An improved experimental model for peripheral neuropathy in rats. Braz $J$ Med Biol Res 2013; 46: 253-256, doi: 10.1590/1414-431X 20122462.

13. Xu B, Descalzi G, Ye HR, Zhuo M, Wang YW. Translational investigation and treatment of neuropathic pain. Mol Pain 2012; 8: 15, doi: 10.1186/1744-8069-8-15.

14. Basbaum Al, Bautista DM, Scherrer G, Julius D. Cellular and molecular mechanisms of pain. Cell 2009; 139: 267284, doi: 10.1016/j.cell.2009.09.028.

15. Eccleston C, Cooper TE, Fisher E, Anderson B, Wilkinson NM. Non-steroidal anti-inflammatory drugs (NSAIDs) for chronic non-cancer pain in children and adolescents. Cochrane Database Syst Rev 2017; 8: CD012537.

16. Syriatowicz JP, Hu D, Walker J, Tracey D. Hyperalgesia due to nerve injury: role of prostaglandins. Neuroscience 1999; 94: 587-594, doi: 10.1016/S0306-4522(99)00365-6.

17. Zimmermann $M$. Ethical guidelines for investigations of experimental pain in conscious animals. Pain 1983; 16: 109-110, doi: 10.1016/0304-3959(83)90201-4.

18. Vivancos GG, Verri WA Jr, Cunha TM, Schivo IR, Parada $\mathrm{CA}$, Cunha $\mathrm{FQ}$, et al. An electronic pressure-meter nociception paw test for rats. Braz J Med Biol Res 2004; 37: 391-399, doi: 10.1590/S0100-879X2004000300017.

19. Ferreira SH, Moncada S, Vane JR. Indomethacin and aspirin abolish prostaglandin release from the spleen. Nat New Biol 1971; 231: 237-239, doi: 10.1038/newbio231237a0.

20. Ferreira SH, Moncada S, Vane JR. Further experiments to establish that the analgesic action of aspirin-like drugs depends on the inhibition of prostaglandin biosynthesis. $\mathrm{Br} J$ Pharmacol 1973; 47: 629P-630P, doi: 10.1111/j.1476-5381. 1973.tb08157.x

21. Carvalho TT, Borghi SM, Pinho-Ribeiro FA, Mizokami SS, Cunha TM, Ferreira SH, et al. Granulocyte-colony stimulating factor (G-CSF)-induced mechanical hyperalgesia in mice: role for peripheral TNF $\alpha, \mathrm{IL}-1 \beta$ and IL-10. Eur J Pharmacol 2015; 749: 62-72, doi: 10.1016/j.ejphar.2014.12.023.

22. Attal N, Cruccu G, Haanpää M, Hansson $P$, Jensen TS, Nurmikko T, et al. EFNS guidelines on pharmacological treatment of neuropathic pain. Eur J Neurol 2006; 13: 11531169, doi: 10.1111/j.1468-1331.2006.01511.x.

23. Dworkin RH, Connor AB, Backonja M, Farrar JT, Finnerup NB, Jensen TS, et al. Pharmacologic management of neuropathic pain: evidence-based recommendations. Pain 2007; 132: 237-251, doi: 10.1016/j.pain.2007.08.033.

24. Meek IL, Van de Laar MAFJ, E Vonkeman H. Non-steroidal anti-inflammatory drugs: an overview of cardiovascular risks. Pharmaceuticals (Basel) 2010; 3: 2146-2162, doi: 10.3390/ph3072146.

25. Guyer PB. To-Day's drugs. Indomethacin. Br Med J 1964; 2: 429, doi: $10.1136 / \mathrm{bmj} .2 .5406 .427$.

26. Steinmeyer J. Pharmacological basis for the therapy of pain and inflammation with nonsteroidal anti-inflammatory drugs. Arthritis Res 2000; 2: 379-385, doi: 10.1186/ar116.

27. Rainsford KD. Anti-inflammatory drugs in the 21st century. Subcell Biochem 2007; 42: 3-27, doi: 10.1007/1-4020-5688-5.

28. Brune K, Patrignani P. New insights into the use of currently available non-steroidal anti-inflammatory drugs. $J$ Pain Res 2015; 8: 105-118, doi: 10.2147/JPR.S75160.

29. Stock JL, Shinjo K, Burkhardt J, Roach M, Taniguchi K, Ishikawa $\mathrm{T}$, et al. The prostaglandin E2 EP1 receptor mediates pain perception and regulates blood pressure. J Clin Invest 2001; 107: 325-331, doi: 10.1172/JCI6749.

30. Luo C, He M, Bohlin L. Is COX-2 a perpetrator or a protector? Selective COX-2 inhibitors remain controversial1. Acta Pharmacol Sin 2005; 26: 926-933, doi: 10.1111/j.17457254.2005.00150.x.

31. Rainsford KD. Current status of the therapeutic uses and actions of the preferential cyclo-oxygenase-2 NSAID, nimesulide. Inflammopharmacology 2006; 14: 120-137, doi: 10.1007/s10787-006-1505-9.

32. Kimura T, Iwase M, Kondo G, Watanabe H, Ohashi M, Ito D, et al. Suppressive effect of selective cyclooxygenase-2 inhibitor on cytokine release in human neutrophils. Int Immunopharmacol 2003; 3: 1519-1528, doi: 10.1016/ S1567-5769(03)00179-6.

33. Delaney B. Safety Assessment of Foods Obtained from Crops Developed Using Biotechnology. Chichester: John Wiley \& Sons; 2009.

34. Ohsawa $\mathrm{M}$, Yamamoto $\mathrm{S}$, Ono $\mathrm{H}$. Contribution of the sensitization of supraspinal nociceptive transmission in chronic pain [in Japanese]. Yakugaku Zasshi 2014; 134: 387-395, doi: 10.1248/yakushi.13-00236-3.

35. Napoli I, Noon LA, Ribeiro S, Kerai AP, Parrinello S, Rosenberg $\mathrm{LH}$, et al. A central role for the ERK-signaling pathway in controlling Schwann cell plasticity and peripheral nerve regeneration in vivo. Neuron 2012; 73: 729-742, doi: 10.1016/j.neuron.2011.11.031.

36. Zuo Y, Perkins NM, Tracey DJ, Geczy CL. Inflammation and hyperalgesia induced by nerve injury in the rat: a key role of 
mast cells. Pain; 105: 467-479, doi: 10.1016/S0304-3959 (03)00261-6.

37. Kuner $\mathrm{R}$, Flor $\mathrm{H}$. Structural plasticity and reorganisation in chronic pain. Nat Rev Neurosci 2016; 18: 20-30, doi: 10.1038/nrn.2016.162.

38. White FA, Jung $H$, Miller RJ. Chemokines and the pathophysiology of neuropathic pain. Proc Natl Acad Sci USA 2007; 104: 20151-20158, doi: 10.1073/pnas.0709250104.
39. Ratté S, Prescott SA. Afferent hyperexcitability in neuropathic pain and the inconvenient truth about its degeneracy. Curr Opin Neurobiol 2016; 36: 31-37, doi: 10.1016/j.conb. 2015.08.007.

40. Parada CA, Reichling DB, Levine JD. Chronic hyperalgesic priming in the rat involves a novel interaction between cAMP and PKCE second messenger pathways. Pain 2005; 113: 185-190, doi: 10.1016/j.pain.2004.10.021. 